\title{
An Efficient Upgradation of STATCOM to PV-STATCOM and Result Estimation using SIMULINK
}

\section{A. Clement Raj, Ararso Taye Waktola}

\begin{abstract}
Power generation is a much discussed topic in research works recently. Power production from different renewable source were the most processed topic. There are large number of solar farms which produce heavy electricity throughout the world but the overall efficiency of those solar farms remain unutilized especially in morning and evening when the sunlight is at its minimum the power production is too low. The series of Photovoltaic Cells $(P V)$ are responsible for power production which are connected with the grid. The solar power output is D.C which can be transformed into A.C by inverter injection in the production line. STATCOM is proposed system which is a device is coming from the sub categorization of FACTS. STATCOM is concentrated on voltage source transformer. It operates in accordance as rectifier and inverter is used to increase power transmission limits. It also has the feature of damping control. The overall gist of the system is we propose a PV-STATCOM control concept. We use MATLAB 2013a to develop a Simulink simulation of PV-STATCOM system. It will be a solar inverter which is voltage controlled and it has overall inverter properties too.
\end{abstract}

\section{Index Terms: FACTS, STATCOM, PV-STATCOM, MATLAB}

\section{INTRODUCTION}

There are plenty of renewable and non-renewable sources of power production. Conventional non-renewable sources were popular from year's .In recent studies non-renewable power production took the first place.

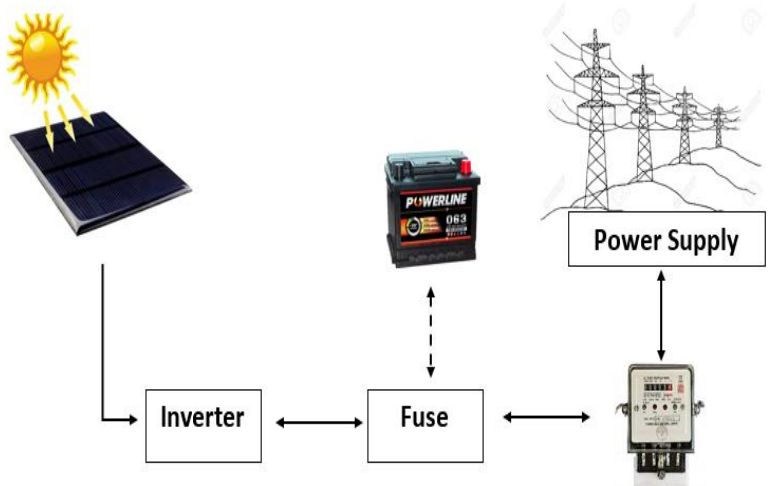

Fig. 1.1 - Basic Configuration of Solar PV System

The main drawbacks for the renewable power production is its processing and efficiency utilization but most of the researches involved the power production alone. Generation of power production from renewable sources like solar, tidal, wind and hydroelectricity are popular today. Except solar all other power production systems are unpredictable. When the tide, wind or hydro power will be at peak is not abstract. Solar power plants are always installed on the places after several

researches like places where the sunlight is available throughout the year, the intensity of sunlight is high, rain is less throughout the year etc. The solar power is most efficient renewable power source on the Earth now. We concentrate our study over the power production management and its efficiency management using PVSTACOM. We deal with the inverting circuits to maintain the output efficiency. The results is validated using MATLAB system of simulation. It is the most reliable simulator available today to validate the power electronics and system research. Its simulator have almost all modules and results are almost equal to the real-time implementations. It's highly efficient simulation can provide us the result which we can estimate for real word implementations.

\section{LITERATURE SURVEY}

Mohammed Khorshed Alam and Faisal Khan explained in their IEEE paper in 2013 about subcell interconnection for solar cells [1]

They explained that multifunction solar cells can produce more power from solar energy with respect to single junction cells. They further explained that very less research has been done on the identification of correct interconnection of multi junction solar cells using power electronic design. They worked over Maximum Power Point Tracking (MPPT) by efficiently designing it for single power point for multiple solar modules. It reduced the design complexity and helped to produce the result in much lower money spent over lengthier MPP tracking systems. Their concentration was mainly over the implementation overhead and to reduce the design difficulties. The possible results implementation and outcome were discussed extensively.

Rikiya Abe and Hisao Taoka researched in their IEEE paper in 2011 about the communicative electrical Grids. [2]

They discussed and researched over capacity transmission lines which increases the synchronization with multiple grids. It is highly required to increase the transmission rate and they broke the design of larger grids into smaller segmented grids. All these grids are digitally connected using internet addresses which makes them much smarter compared to conventional grids.

Revised Manuscript Received on August 05, 2019.

A. Clement Raj, Lecturer in Bule Hora University, Ethiopia

Mr.Ararso Taye Waktola, Head of Electrical and Computer Engineering,department, Bule Hora University, Ethiopia. 
All the segmented grids communicate with each other and uses the conventional transmission lines. This was the first initiation towards the smart grids which lead us to have smarter sub grids which are very useful for the efficient transmission of power.

Xiong Liu, Penganga and Poh Chianglob explain in their IEEE paper in 2011 about the coordination control of hybrid AC/DC micro grids. [3]

They explained the combined initiative about the AC-DC micro grids. In an individual $\mathrm{AC}$ or $\mathrm{DC}$ grid multiple process of DC-AC-DC or AC-DC-AC transformations take place. Multiple directional converters work together to produce the output in combine AC/DC grid.

The main issue today in power conversion system is connected in lower voltage distribution systems. More DC devices like LED and EVs are connected on AC power socket to reduce the power consumptions and environment pollutions. If the power is possible at nearer places then there is no need to transmit it from the longer points and get transmission loss. The system initiates with much smarter power conversion system by combining the benefits of control systems and power electronics.

Eduardo Roman and Richardo Alonso researched in their IEEE paper in 2006 about Smarter Photovoltaic module for grid photovoltaic systems. [4]

They researched that there is always a huge loss of almost $1 / 5$ th to $1 / 4$ th of power during integrated photovoltaic system power production. The most eminent reason is due to variation in current. If we use the correct electronic injection in the system these losses can be minimal. They wanted to create an efficient converter which works over DC-DC converter with MPPT. Their result shows the power wastage got controlled to its maximum level. It helped to provide lighter power with lower cost and higher efficiency.

\section{DATA ANALYSIS AND RESEARCH CONTENTS}

The Photovoltaic System converts the solar energy into electrical energy by means of photovoltaic transformations. It has many advantages over the conventional sources of renewable energy like lowest possible carbon footprint, low maintenance, long life and much installation cost.

In fig. 1.1 the multiple components are arranged in proper order to efficiently transfor the Sun rays to electrical energy. The system is always affixed with the Inverter to convert the Direct Current to Alternating Current. The battery can be used to save the solar converted electrical energy to the battery and supply to the load. Direct solar transformation to the electric electric energy is possible but it can not save the energy in that case. The fuse is used to maintain the safety of the system, if it is found to be short circuit or very high power fluctuations the fuse saves the whole circuitry by closing the connection. The meter is present to calculate the power rating and grid is used to intake/outtake the power produced and stored.

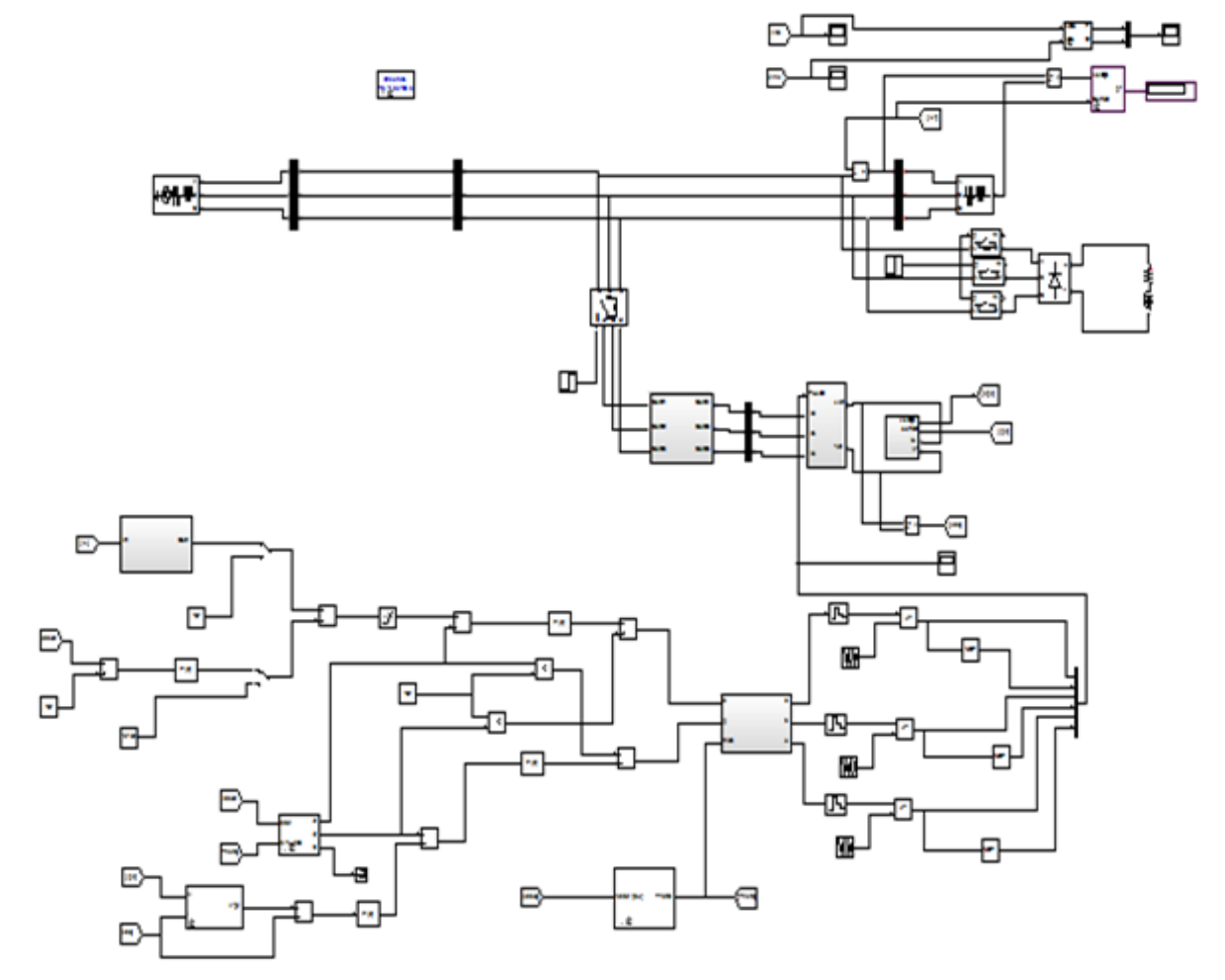

Fig. 1.2 - PV STATCOM System with Solar Panel transformations.

This is the overall design of our PV-STATCOM system which includes the solar panel which consumes the power 


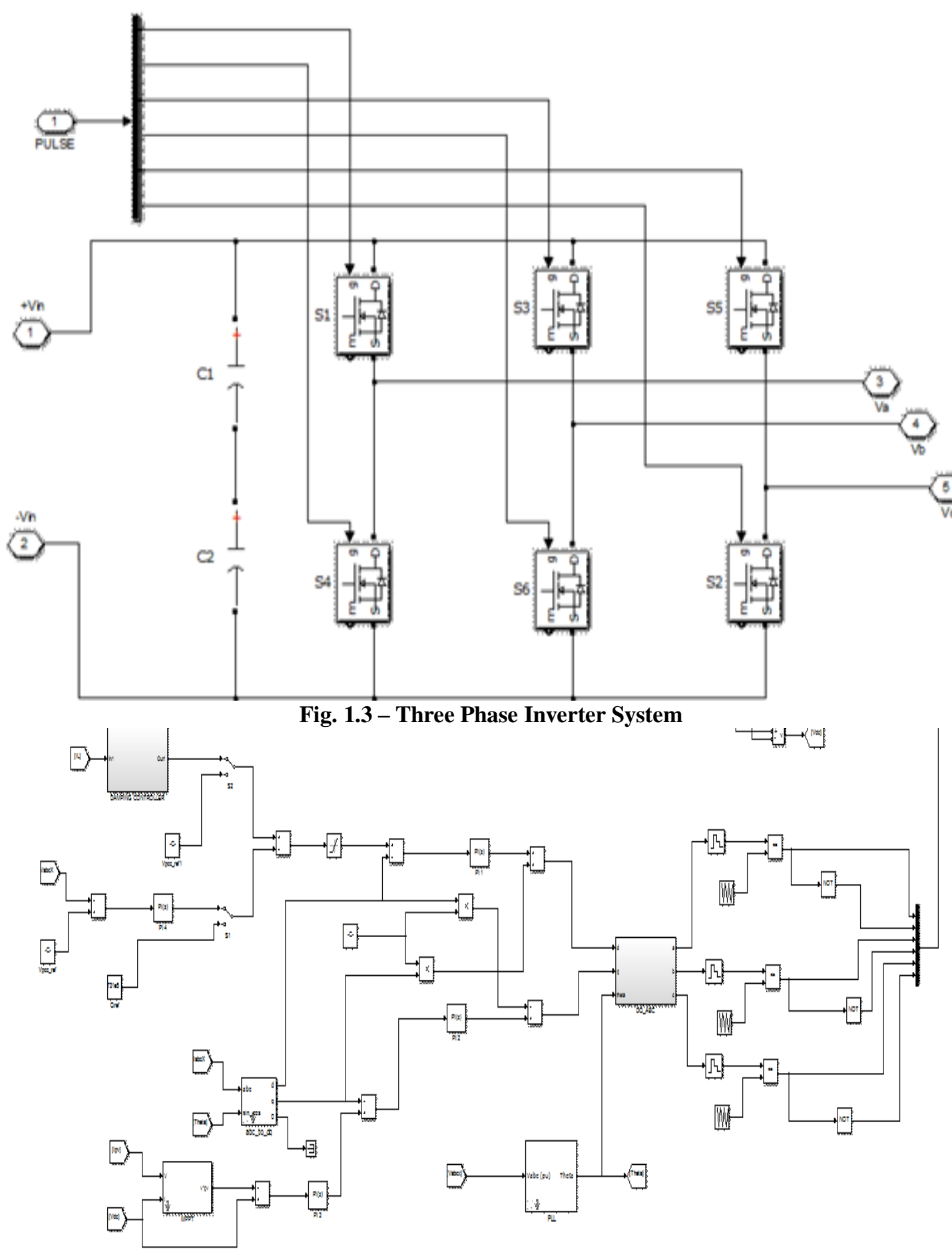

Fig. 1.4 - The Control Technique

\section{RESULTS AND OUTPUTS}

The pulses to the 3 phase inverter consist of 6 switches as shown below. The converter produces an AC sinusoidal voltage, in phase with the line voltage. 


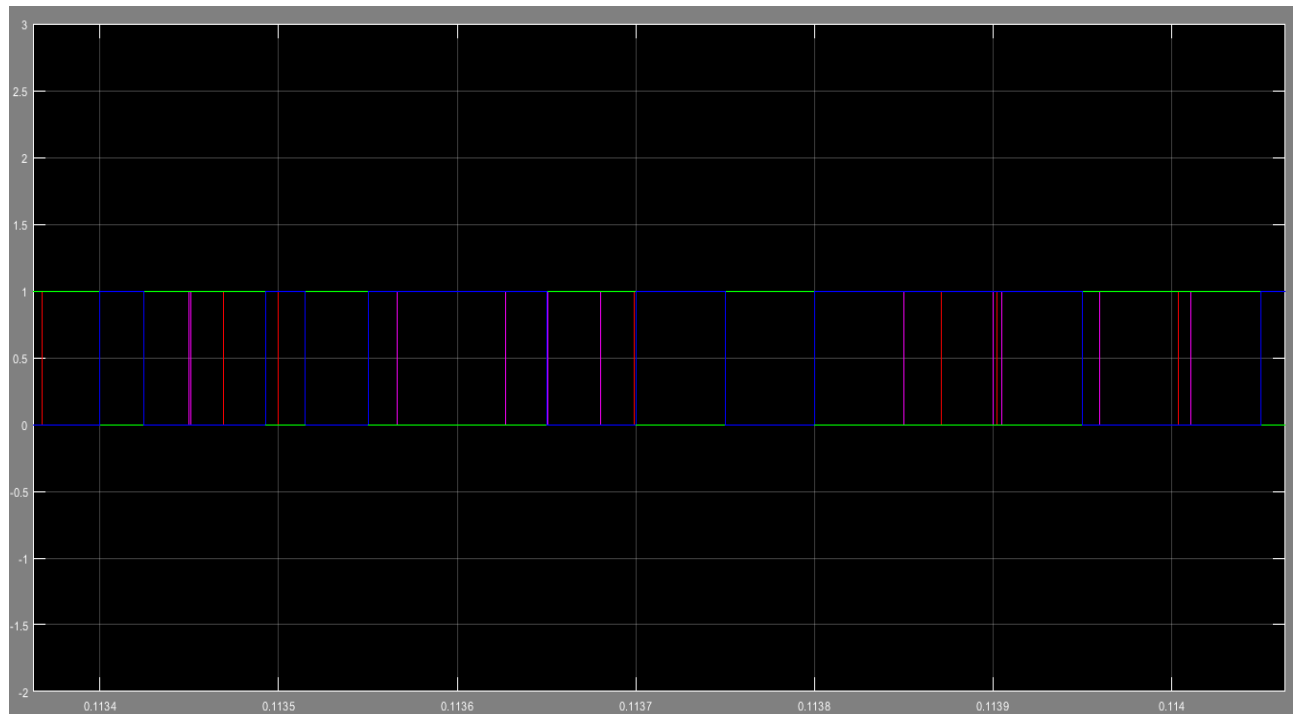

Fig. 1.5- Gate Pulses

change is shown in the figure. When the PS-STATCOM is

The load voltage and Load current are shown in below connected to the line, the voltage is again regulated.

figures. They are in-phase with each other. A transient

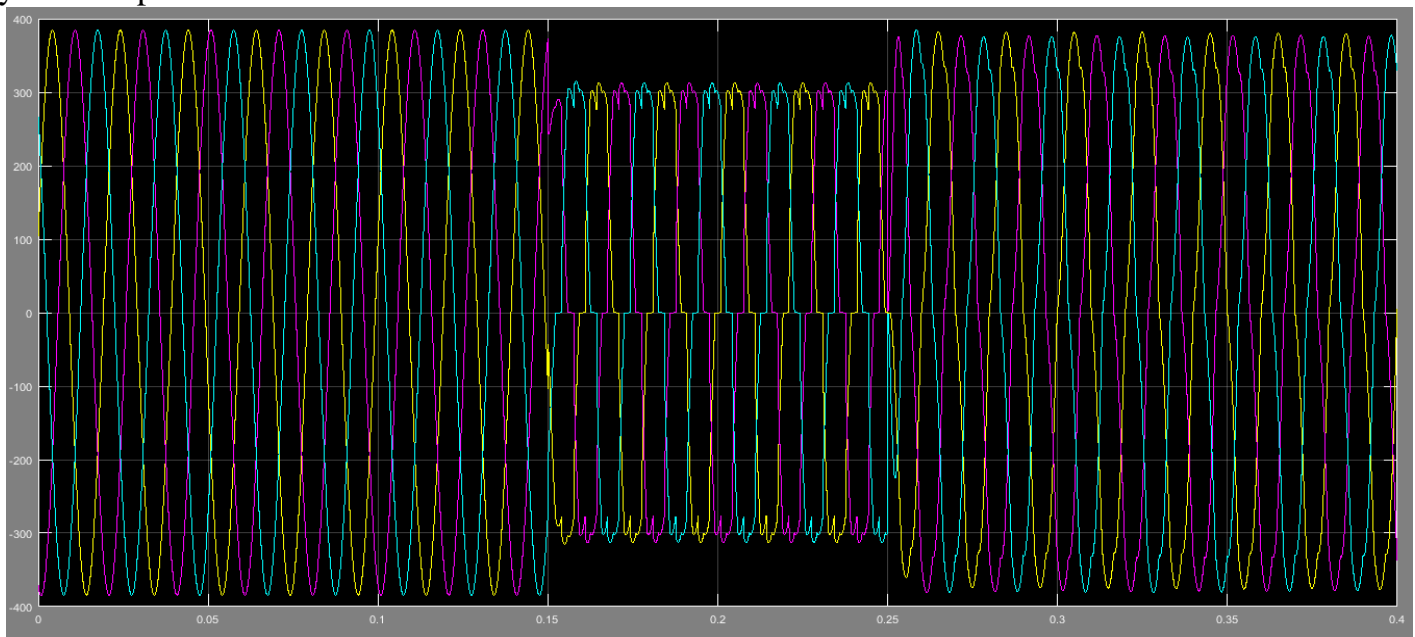

Fig. 1.6 - Load Voltage

The load current is shown during the normal condition. During the transient change, the load current is maintained constant with the help of PV-STATCOM as shown below.

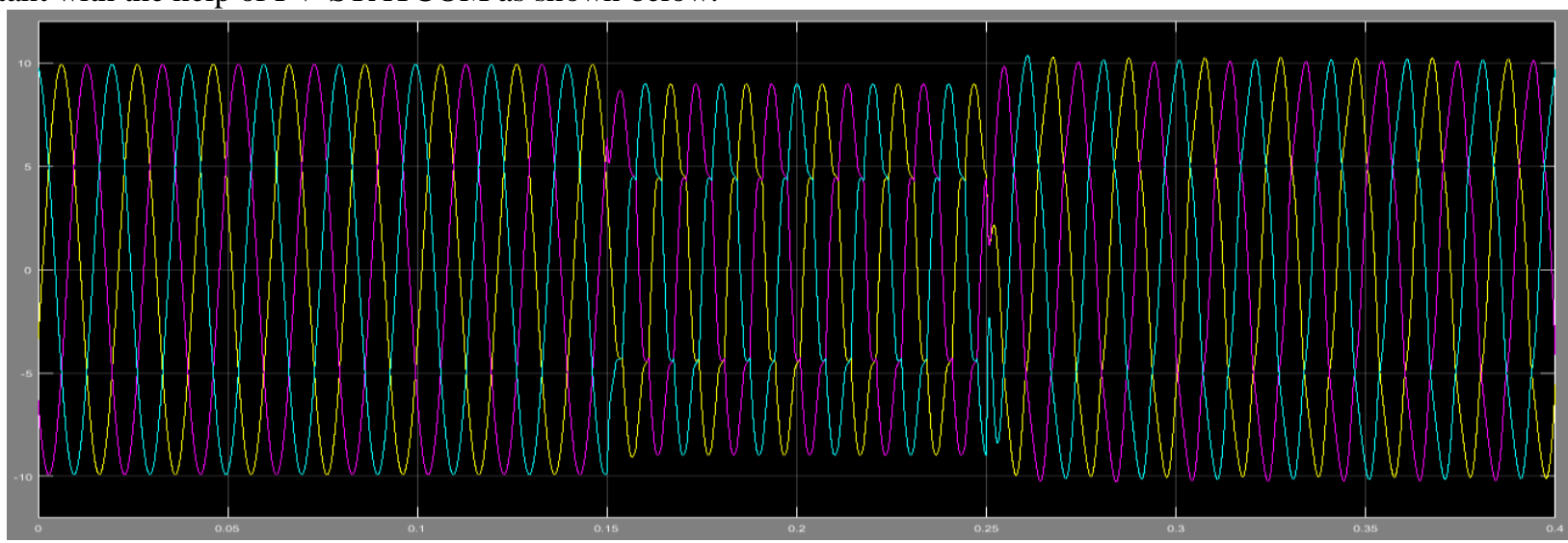

Fig. 1.7 - Load Current

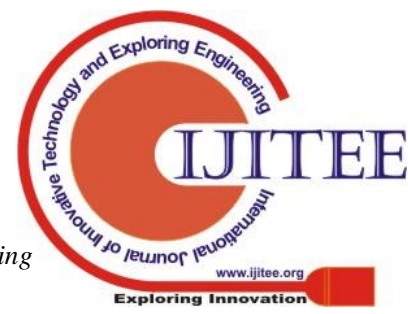




\section{A. Power Factor}

A near unity power factor is achieved when the load current is exactly in-phase with the load voltage.

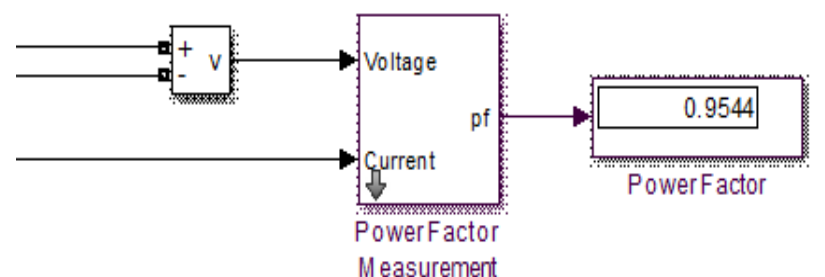

Fig. 1.8 Power Factor Improvement

\section{B. Real And Reactive Power}

The real power drops and the reactive power flowing in the circuit is increased during a transient change in the system at 0.15 . The power levels are regulated as shown below at 0.25 by the use of Solar PV-STATCOM panel.

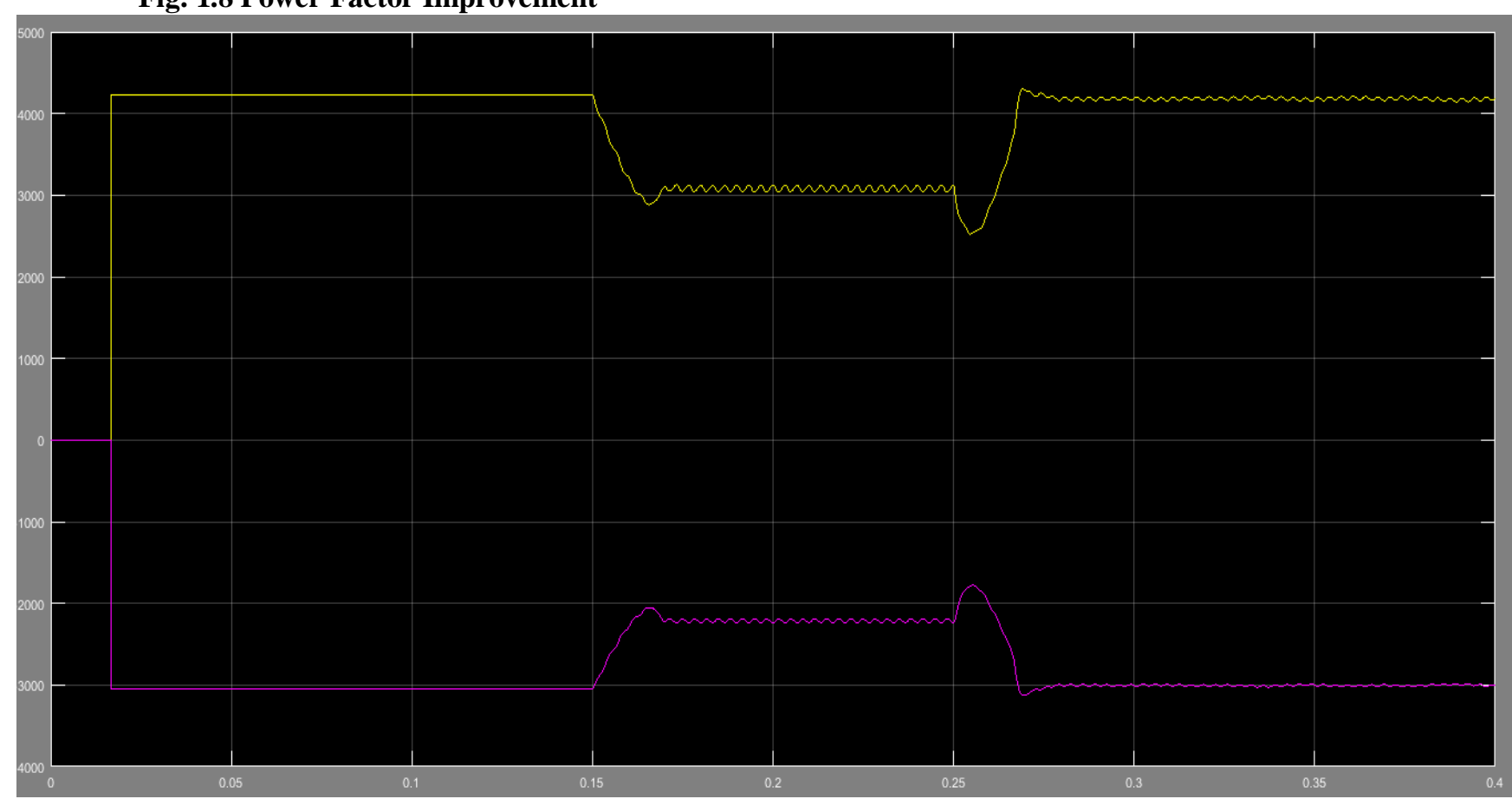

Fig. 1.9 - Real and Reactive Power Compensation

\section{THD Before Compensation:}

A high value of Total harmonic distortion is observed, before compensation when the non-linear loads are connected is shown as below. The PV based STATCOM acts upon the system with non linear load. The amount of harmonic content is reduced to a great extent by the filtering action of the PV based STATCOM.

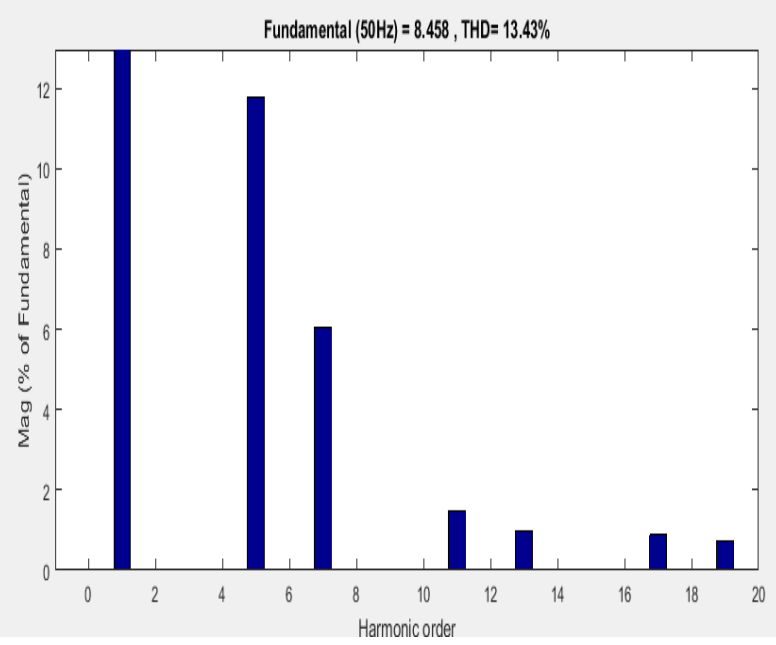

Fig. 1.10 - THD before Compensation

\section{THD After Compnsation:}

The THD is reduced after the reactive power compensation / harmonic compensation is made with the PV-STATCOM device. THD: $\%$ as shown in the below figure.

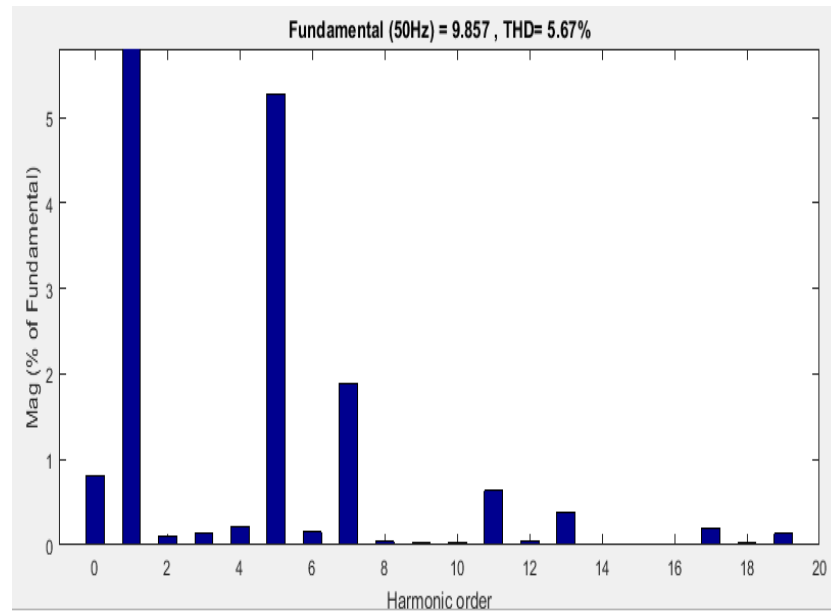

Fig. 1.11 - THD after compensation

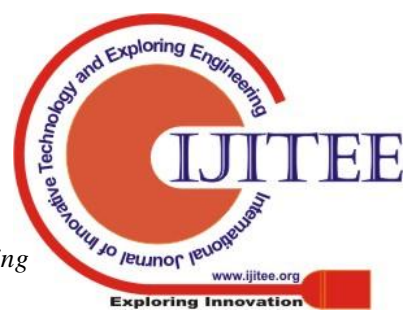




\section{CONCLUSION}

The proposed concept utilizes a PV solar farm as a STATCOM on a $24 / 7$ basis, for supporting the grid as needed. The conventional smart inverters are unable to provide voltage control during large dips in grid voltage due to large disturbances occurring around noon hours. Moreover, their response time under volt/var control is in the range of 1-2 sec. The proposed smart inverter PVSTATCOM overcomes both these limitations. It operates as a STATCOM with full inverter capacity in nighttime as well as during any time of the day to provide critical grid support. During a large system disturbance during daytime, it discontinues its real power generation function for a short period, typically a few seconds, and releases its entire inverter capacity for STATCOM operation. It returns to normal pre-disturbance power production as soon as the need for grid support is fulfilled. The response of the proposed smart inverter (1-2 cycles) matches that of an actual STATCOM. The performance of different modes of operation of the modeled PV-STATCOM, during night and day has been verified using MATLAB simulation studies. This PV-STATCOM function also opens up a potential revenue making opportunity for the PV solar farm by providing similar grid support functions at critical times as an actual STATCOM in practical applications.

\section{REFERENCE}

1. L. F. Casey, C. Schauder, J. Cleary, and M. Ropp, "Advanced inverters facilitate high penetration of renewable generation on medium voltage feeders impact and benefits for the utility," in Innovative Technologies for an Efficient and Reliable Electricity Supply (CITRES), 2010 IEEE Conference on, Sept 2010, pp. 86-93.

2. R. K. Varma, S. A. Rahman, V. Atodaria, S. Mohan, and T. Vanderheide, "Technique for fast detection of short circuit current in pv distributed generator," IEEE Power and Energy Technology Systems Journal, vol. 3, no. 4, pp. 155-165, Dec 2016.

3. B. Mather, "NREL/SCE high-penetration PV integration project: Reporton field demonstration of advanced inverter functionality in Fontana,CA," National Renewable Energy Laboratory (NREL), Golden, CO.Tech. Rep., 2014, Report NREL/TP-5D00-62483.

4. Yazdani and R. Iravani, Voltage-sourced converters in power systems: modeling, control, and applications. John Wiley \& Sons, 2010. [24] A. Yazdani, A. R. D. Fazio, H. Ghoddami, M. Russo, M. Kazerani, J. Jatskevich, K. Strunz, S. Leva, and J. A. Martinez, "Modeling guidelines and a benchmark for power system simulation studies of three-phase single-stage photovoltaic systems," IEEE Transactions on Power Delivery, vol. 26, no. 2, pp. 1247-1264, April 2011.

5. M. Liserre, F. Blaabjerg, and S. Hansen, "Design and control of an lclfilter-based three-phase active rectifier," IEEE Transactions on Industry Applications, vol. 41, no. 5, pp. 1281-1291, Sept 2005. [26] W. Leonhard, Control of electrical drives. Springer Science \& Business Media, 2001.

6. R. K. Varma, V. Khadkikar, and S. A. Rahman, "Utilization of distributed generator inverters as STATCOM," Sep. 15 2010, PCT Patent application PCT/CA2010/001419.
7. E. M. Siavashi, "Smart PV inverter control for distribution systems," in Electronic Thesis and Dissertation $\quad 3065$. https://ir.lib.uwo.ca/etd/3065, 2015.

8. R. K. Varma, S. A. Rahman, A. C. Mahendra, R. Seethapathy, and T. Vanderheide, "Novel nighttime application of PV solar farms as STATCOM (PVSTATCOM)," in 2012 IEEE Power and Energy Society General Meeting, July 2012, pp. 1-8.

9. EPRI, "Common functions for smart inverters, version 3," Palo Alto, CA, Feb 2014.

10. R.K. Varma, V. Khadkikar, and R. Seethapathy, "Nighttime application of PV solar farm as STATCOM to regulate grid voltage," IEEE Transactions on Energy Conversion, vol. 24, no. 4, pp. 983-985, Dec 2009.

11. R. K. Varma, "Multivariable modulator controller for power generation facility," filed on December 2014, PCT Application (PCT/CA2014/051174).

12. Benot Bletterie, Serdar Kadam, Roman Bolgaryn, and Antony Zegers. Voltage Control with PV Inverters in Low Voltage Networks - In Depth Analysis of Different Concepts and Parameterization Criteria. IEEE TRANSACTIONS ON POWER SYSTEMS, 32(1), 2017. doi: 10.1109/TPWRS.2016.2554099.

13. R. K. Varma, S. A. Rahman, and T. Vanderheide, "New control of PV solar farm as STATCOM (PVSTATCOM) for increasing grid power transmission limits during night and day," IEEE Transactions on Power Delivery, vol. 30, no. 2, pp. 755-763, April 2015.

14. Dinavahi, R. Iravani, and R. Bonert, "Design of a realtime digital simulator for a d-statcom system," IEEE Transactions on Industrial Electronics, vol. 51, no. 5, pp. 1001-1008, Oct 2004.

15. K. Turitsyn, P. Sulc, S. Backhaus, and M. Chertkov, "Options for control of reactive power by distributed photovoltaic generators," Proceedings of the IEEE, vol. 99, no. 6, pp. 1063-1073, June 2011.

16. T. Stetz, F. Marten, and M. Braun, "Improved low voltage grid integration of photovoltaic systems in Germany," in 2013 IEEE Power Energy Society General Meeting, July 2013, pp. 1-1

\section{AUTHORS PROFILE}

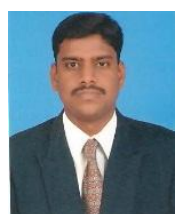

. A. Clement Raj M.E received his B.E (Electrical and Electronics Engineering) from Anna University and M.E (Power Electronics and Drives) from Anna University. He has teaching experience of more than 10 years. Currently works as Lecturer in BULE HORA UNIVERSITY, ETHIOPIA since October 2015, he guided more than 15 UG projects and published several research papers in reputed journals. His areas of interest includes Power Electronics, Electrical Machines and Power system Analysis.

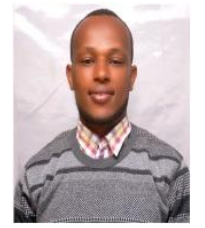

Mr. Ararso Taye Waktola, received his B.Sc. in Electrical and Computer Engineering (Electrical Power Engineering) from Debre Markos University, Ethiopia during July 6/2015Gc. He did his Masters of Technology (M.Tech) in Power System Engineering at Parul University, India during June 2018GC. Currently he works as the head of Electrical and Computer Engineering department at Bule Hora University, Ethiopia. 